\title{
Material Compressing Test of the High Polymer Part Used in Draft Gear of Heavy Load Locomotive
}

\author{
Yangang WEI ${ }^{1, \mathrm{a}}$, Wang Zhang ${ }^{1, \mathrm{~b}}$, Yaxin $\mathrm{SONG}^{2, \mathrm{c}}$ and Fayuan $\mathrm{ZHU}^{3, \mathrm{~d}}$ \\ ${ }^{1}$ School of Mechanical Engineering, Dalian Jiaotong University, Dalian 116028, China \\ ${ }^{2}$ Zhongche Datong Electric Power Locomotive Limited Company, Datong 037038, China \\ ${ }^{3}$ Taizhou Duobang Polymer Science and Technology Limited Company, Taizhou 318020, China \\ aweiyg@djtu.edu.cn b460815759@qq.com csongyax@163.com d2934474457@qq.com
}

\begin{abstract}
According to the actual load cases of heavy load locomotive, the material compressing tests of the high polymer parts used in the locomotive are researched. The relationship between stress and strain during the material compressing are acquired by means of comparing the many results of the material compressing tests under different test condition. The relationship between stress and strain during the material compressing is nonlinear in large range of strain, but the relationship is approximately linear in small range of strain. The material of the high polymer made in China and the material of the high polymer imported are compared through the tests. The results show that the compressing property of the material of the high polymer made in China and the material of the high polymer imported are almost same. The research offers the foundation to study the structure elasticity of the draft gear.
\end{abstract}

Keywords: Compressing Test, High polymer, Draft gear, Locomotive

\section{Introduction}

Along with the development of modern industry, every country put forward higher and higher technical demand of railway and the demand make the technical level of the railway equipment much higher than before. As one of key devices of the railway equipment, draft gear passes the loads, abates impact, absorbs energy and reduces vibration during locomotive starting up, braking and bumping between the vehicle to decrease the damage of cargo and vehicles and to keep the running stability of the vehicles [1].

The technical level of heavy load railway equipment of China is improved much more than before and is now in advanced range of the world. At present, freight transport of railway in China is developing along with the direction of heavy load with high speed. Reviewing the development of main draft gears used in locomotive and vehicle in China, large capacity draft gears, MT-2, MT-3 and ST etc, are developed after three stages of the development. The practice of draft gear use proves that the technical level of the draft gear has obtained swift progress in quality. As the heavy work on railway freight transport become aggravated, the draft gear with the large capacity and high ability of absorbing energy is now needed in China [2]. 
So far, among of the draft gears of the railway used at home and abroad, vapor steam draft gear and rubber mud draft gear have good buffering property, but their reliability are not so good. Rubber draft gear has a low capacity. Draft gear with steel rub elements has high reliability, but its buffering ability is not stable and discreteness is large. Draft gear with rubber-mud rub elements and draft gear of hydraulic pressure with rub elements have excellent buffering ability, however, their structures are complicated and their reliabilities are lower [3 6].

The high polymer elasticity element draft gear has very good antiaging property and the sensitivity to temperature is much lower than that of rubber. Its ability to absorbing energy is strong and its buffering property is stable. Both of maximum resistant force and capacity of the draft gear are big. Its reliability is high. However, the constitutive relation of the high polymer and the structure elasticity of the high polymer draft gear can not be found in published documentation in China. So the present paper researches the material test of the high polymer in detail in order to obtain the relationship between stress and strain during the material compressing and to offer the foundation for studying the structure elasticity of the draft gear. The material of the high polymer made in China and the material of the high polymer imported are compared through the tests in the paper.

\section{Compressing Test of the Material of the high polymer Imported.}

The test equipment which is used to compress the material of the high polymer is AG-IC100KN electronic all-purpose material test machine. The equipment with computer possesses the function to collect, to record and to deal handle data automatically. Its displacement precision is micron grade, its load precision $10^{-3}(\mathrm{~N})$, its stress precision is $10^{-4}(\mathrm{MPa})$ and its strain precision $10^{-5}$. Its load capacity is $100(\mathrm{KN})$. The function of the equipment satisfies the requirement of the stress and strain under the running cases of the locomotive.

The specimens which are made from the material of the high polymer are standard cylinders with diameter $30(\mathrm{~mm})$ and height $10(\mathrm{~mm})$. The part on the left is elasticity element of the high polymer and three specimens on the right are made from the material of the high polymer in the Fig.1 (a).
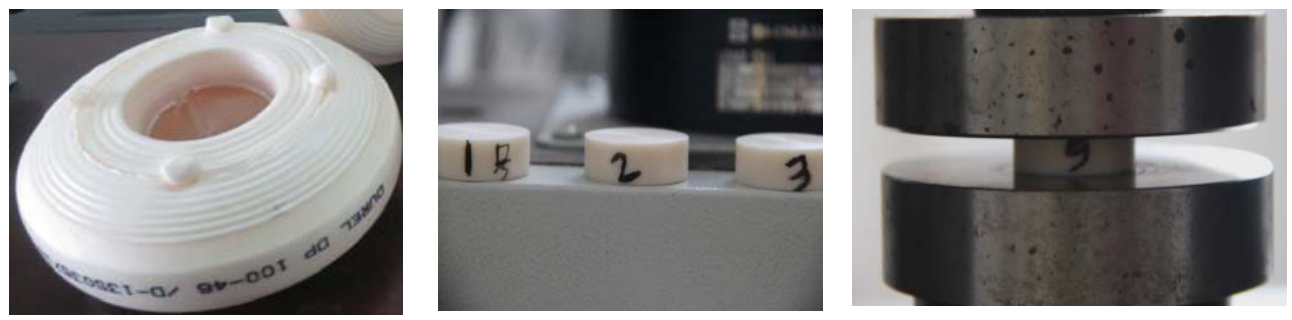

(a) The high polymer part of draft gear and the specimens (b) one of the specimens being compressed

Fig. 1 The high polymer part of draft gear and the specimens

Before doing formal test, several preparatory tests have been done and the test scheme has been made according to the property showed up by the specimens of the high polymer. The test program is that tests are divided into three groups by the compressing amount. The compressing amount of specimens of three groups are respectively $5(\mathrm{~mm}), 4(\mathrm{~mm})$ and 3 $(\mathrm{mm})$. In order to keep the stability of the test data, three specimens are compressed by 5 $(\mathrm{mm})$, three specimens are compressed by $3(\mathrm{~mm})$ and six specimens are compressed by 4 $(\mathrm{mm})$. To observe the constitutive relation of the high polymer after several compressions, 
every specimen which is compressed by $3(\mathrm{~mm})$ is repetitively compressed 20 times, every specimen which is compressed by $4(\mathrm{~mm})$ is repetitively compressed 16 times and every specimen which is compressed by $5(\mathrm{~mm})$ is repetitively compressed 12 times. In this way, the completeness and reliability of the test data can be ensured. One of the specimens is being compressed in Fig.1 (b).

The typical curves of the relationship between stress and strain of specimens which is compressed by $3(\mathrm{~mm})$ are showed in Fig 2 because the main characteristic of the curves of specimens compressed by $4(\mathrm{~mm})$ and compressed by $5(\mathrm{~mm})$ are similar to those of specimens compressed by $3(\mathrm{~mm})$.

It is showed in Fig. 2 that the range of stress is from 0 to $60(\mathrm{MPa})$ and the range of strain is from 0 to about 0.3 when specimen is compressed by $3(\mathrm{~mm})$ in first time. The relationship between stress and strain is generally nonlinear in whole range, but is approximately linear in range from 40 to $60(\mathrm{MPa})$.

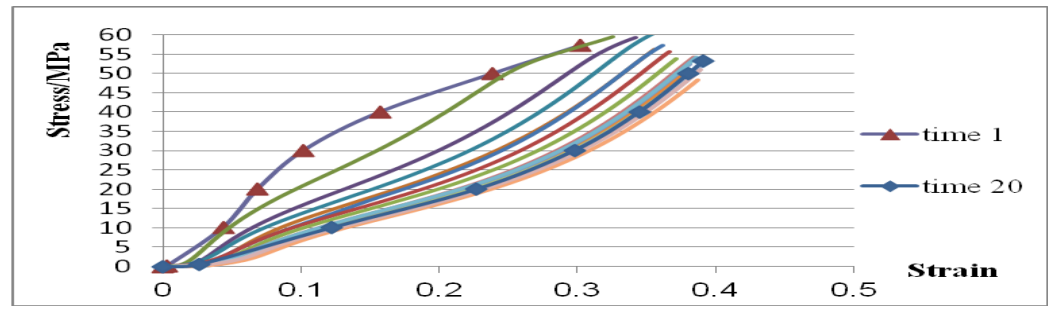

Fig .2 The typical test curves of the imported specimens compressed by $3(\mathrm{~mm})$

Locomotive often starts or accelerates and brakes or decelerates while running, so the draft gears used in the railway vehicles are compressed repetitively. It is necessary to study the constitutive relation while the material of the high polymer is repetitively being compressed. After many tests, it is found that the constitutive relation of the specimen is ceaselessly changed in certain times. However, the constitutive relation becomes stable and stops changing when the times of test reaches a certain number. For example, the constitutive relation of the specimen is ceaselessly changed from first time to eighth time and the constitutive relation of the specimen becomes stable and stops changing (the curves of the relationship between stress and strain are overlap to be one curve)from ninth time to twentieth time, see Fig.2. It is also showed in Fig.2 that the shape of the curves of the relationship between stress and strain is varied as the compressing time increase, the gradient of the curve is bigger at the head part and is smaller at the rear part when the number of test time is smaller. The gradient of the curve becomes smaller at the head part and becomes bigger at the rear part when the number of test time is bigger. It is also showed in Fig. 2 that the range of stress is from 0 to about $55(\mathrm{MPa})$ and the range of strain is from 0 to about 0.38 when the number of compressing time is bigger than 9 .

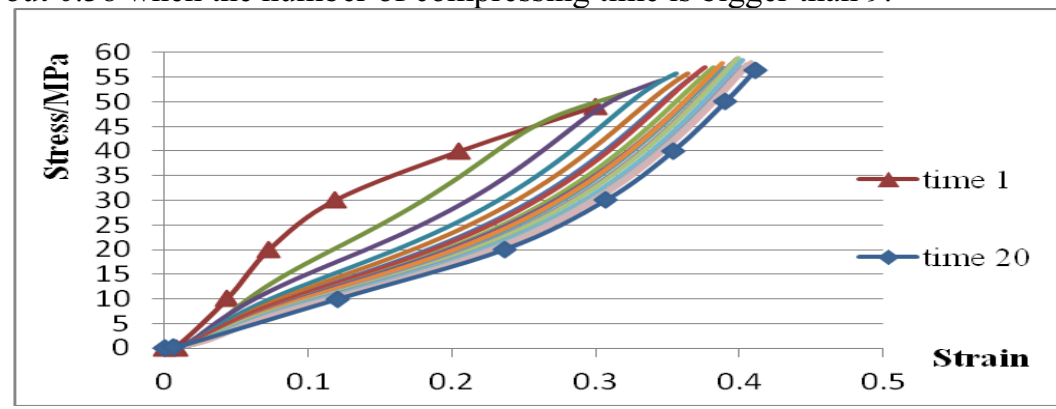

Fig.3 The typical test curves of the domestic specimens compressed by $3(\mathrm{~mm})$ 


\section{Compressing Test of the Material of the high polymer Made in China.}

In order to compare, the test program of the high polymer made in China is same to the test program of the high polymer imported. Every specimen which is compressed by $3(\mathrm{~mm})$ is repetitively compressed 20 times, every specimen which is compressed by $4(\mathrm{~mm})$ is repetitively compressed 16 times and every specimen which is compressed by $5(\mathrm{~mm})$ is repetitively compressed 12 times. The typical curves of the relationship between stress and strain of specimens which is compressed by $3(\mathrm{~mm})$ are respectively showed in Fig.3.

It is obvious that the characteristic of the high polymer made in China is same to that of the high polymer imported through comparing Fig. 2 with Fig.3.

\section{Summary}

It is clear according to the curves of relationship between strain and stress that the gradient of the curve is bigger at the head part and is smaller at the rear part when the number of test time is smaller. The fact illustrates that elastic module is bigger at the head part and is smaller at the rear part, i.e. the material is harder at the head part and is softer at the rear part.

The values of strain and stress at ending point of the curves become larger as the compressing amount increases, but the characteristic of the curves are same. The curve of specimen compressed by $5(\mathrm{~mm})$ is the extension of that of specimen compressed by 3 $(\mathrm{mm})$. The values of strain and stress at ending point of specimen compressed by $3(\mathrm{~mm})$ in first time are about 0.3 and $60(\mathrm{MPa})$ and the values of specimen compressed by $5(\mathrm{~mm})$ are correspondingly about 0.45 and $70 \quad(\mathrm{MPa})$.

It is also showed from the results of the test that the shape of the curves of the relationship between stress and strain is varied as the compressing time increase, the gradient of the curve slowly become smaller at the part of strain less than 0.2 and the gradient of the curve slowly become larger at the part of strain more than 0.2 . It explains that elastic module of the material slowly becomes smaller at the part of strain less than 0.2 and the elastic module slowly becomes larger at the part of strain more than 0.2 as compressing repetitively. However, the constitutive relation becomes stable and stops changing when the times of test reach a certain number (about 10 times).In this case, the elastic module is smaller at the head part and is bigger at the rear part, i.e. the material is softer at the head part and is harder at the rear part..

It is found that the curves of the relationship between stress and strain are similar by comparing correspondingly the curves of specimens imported with the curves of specimens made in China. The fact expresses that the constitutive relations of the two materials are similar and the domestic material can replace the material imported in practice. Table 1 gives the comparing typical test data of the two materials.

\begin{tabular}{|c|c|c|c|}
\hline & $\begin{array}{c}\text { Compressed 20 times by } 3 \\
(\mathrm{~mm})\end{array}$ & $\begin{array}{c}\text { Compressed 16 times } \\
\text { by } 4(\mathrm{~mm})\end{array}$ & $\begin{array}{c}\text { Compressed } 12 \text { times } \\
\text { by } 5(\mathrm{~mm})\end{array}$ \\
\hline imported & $\begin{array}{c}\text { Strain:0 0.4 } \\
\text { Stress:0 53 }(\mathrm{MPa})\end{array}$ & $\begin{array}{c}\text { Strain:0 0.7 } \\
\text { Stress:0 70 }(\mathrm{MPa})\end{array}$ & $\begin{array}{c}\text { Strain:0 0.53 } \\
\text { Stress:0 76 }(\mathrm{MPa})\end{array}$ \\
\hline $\begin{array}{c}\text { made in } \\
\text { China }\end{array}$ & $\begin{array}{c}\text { Strain:0 0.4 } \\
\text { Stress:0 56 }(\mathrm{MPa})\end{array}$ & $\begin{array}{c}\text { Strain:0 0.7 } \\
\text { Stress:0 67 }(\mathrm{MPa})\end{array}$ & $\begin{array}{c}\text { Strain:0 0.54 } \\
\text { Stress:0 76 }(\mathrm{MPa})\end{array}$ \\
\hline
\end{tabular}

Table 1: Typical Test Data Of The High Polymer Imported And The High Polymer Made In China 


\section{Acknowledgment}

The work described in this paper was supported by the grants from Science and Technology Foundation of Education Department of Liaoning Province (L2015099). The financial contributions are gratefully acknowledged.

\section{References}

1. Guoliang HU, Feng LIN and Xeu WANG etc. Study on property of spring rubbing draft gear used in heavy load freight vehicle [J]. Lubricating and Sealing, 2009, 34(7):69 73

2. Liping ZHANG, Jiguang QIN. Principle and application of draft gear [J]. Modern Machine, 1999, 1(1):49 50

3. Jinde ZHANG. Parameter definition of ST draft gear [J]. Railway Vehicle, 1999, $8(8): 6 \sim 10$

4. Li CHENG, Yan JIANG and Li SUN. Research on technology of draft gear used in heavy load freight vehicle [J]. Railway Vehicle, 2007,8(8):6 13

5. Fenggang LIU. 50 year retrospection and expectation of hook and buffer device [J]. Railway Vehicle, 2013, 12(12):62 69

6. Xiaolong WANG, Lianyou YU and Fengzhou WANG. Research on design parameters of domestic draft gear used in heavy load freight vehicle [J]. Railway Vehicle, 2010, 3(3): $8 \sim 12$ 